Trinity University

Digital Commons@ Trinity

Chemistry Faculty Research

Chemistry Department

5-1-2012

\title{
CO Adsorption on Supported Gold Nanoparticle Catalysts: Application of the Temkin Model
}

Christopher J. Pursell

TrinityUniversity, cpursell@trinity.edu

Bert D. Chandler

Trinity University, bchandle@trinity.edu

M. Manzoli

F. Boccuzzi

Follow this and additional works at: https://digitalcommons.trinity.edu/chem_faculty

Part of the Chemistry Commons

\section{Repository Citation}

Pursell, C. J., Chandler, B. D., Manzoli, M., \& Boccuzzi, F. (2012). CO adsorption on supported gold nanoparticle catalysts: Application of the temkin model. Journal of Physical Chemistry C, 116(20), 11117-11125.

This Article is brought to you for free and open access by the Chemistry Department at Digital Commons @ Trinity. It has been accepted for inclusion in Chemistry Faculty Research by an authorized administrator of Digital Commons @ Trinity. For more information, please contact jcostanz@trinity.edu. 


\title{
CO Adsorption on Supported Gold Nanoparticle Catalysts: Application of the Temkin Model
}

\author{
Christopher J. Pursell, ${ }^{, \dagger, *}$ Bert D. Chandler, ${ }^{\dagger}$ Maela Manzoli, ${ }^{\ddagger}$ and Flora Boccuzzi ${ }^{\ddagger}$ \\ ${ }^{\dagger}$ Department of Chemistry, Trinity University, One Trinity Place, San Antonio, Texas 78212, United States \\ ${ }^{\ddagger}$ Department of Inorganic, Physical and Materials Chemistry, and NIS Center of Excellence, University of Torino, Via Pietro Giuria 7, \\ 10125 Torino, Italy
}

ABSTRACT: The adsorption of $\mathrm{CO}$ on the supported gold nanoparticle catalysts $\mathrm{Au} / \mathrm{TiO}_{2}, \mathrm{Au} / \mathrm{Fe}_{2} \mathrm{O}_{3}$, and $\mathrm{Au} / \mathrm{ZrO}_{2}$ was examined using infrared transmission spectroscopy to quantify the isobaric $\mathrm{CO}$ coverage as a function of temperature. The Temkin adsorbate interaction model was then applied to account for the adsorption behavior. To test the general applicability of the Temkin model, this treatment was also applied to three data sets from the literature. This included another real-world catalyst and two model catalysts. All data sets were accurately represented by the Temkin adsorbate interaction model. The resulting thermodynamic metrics are consistent with previous determinations and reflect a particle size-dependence. In particular, the intrinsic adsorption enthalpy at zero $\mathrm{CO}$ coverage varies almost linearly with Au particle size, and this trend appears to be correlated with the abundance of low-coordinate $\mathrm{Au}$

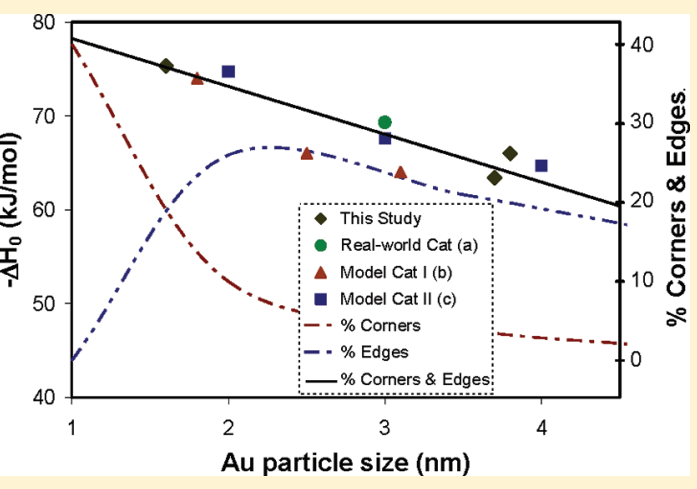
sites (cf., $\mathrm{CN}=6$ and 7 for corners and edges, respectively). For very small particles with mostly $\mathrm{CN}=6 \mathrm{corner}$ sites, the enthalpy reflects strong binding (cf., $-\Delta H_{0} \approx 78 \mathrm{~kJ} / \mathrm{mol}$ ), while for large particles with mostly $\mathrm{CN}=7$ edge sites, the enthalpy reflects weaker binding (cf., $-\Delta H_{0} \approx 63 \mathrm{~kJ} / \mathrm{mol}$ ). The results also suggest that these sites are coupled. This study demonstrates that the Temkin adsorbate interaction model accurately represents adsorption data, yields meaningful metrics that are useful for characterizing nanoparticle catalysts, and should be applicable to other adsorption data sets.

\section{INTRODUCTION}

Of all of the reactions examined on supported metal nanoparticle catalysts, the oxidation of $\mathrm{CO}$ has received extensive experimental and theoretical attention. ${ }^{1}$ While the reaction may appear to be rather straightforward, an understanding of the mechanism has been surprisingly difficult to achieve. Not only is the oxidation of $\mathrm{CO}$ a model system to study, but the adsorption of $\mathrm{CO}$ on gold, a fundamental step in the mechanism, has also become a model interaction to investigate. ${ }^{1}$

Multiple studies indicate that $\mathrm{CO}$ is only weakly chemisorbed on gold. The adsorption is believed to involve low-coordinate sites with coordination number $\mathrm{CN}=6$ (i.e., corners or kinks) and $\mathrm{CN}=7$ (i.e., edges or steps). ${ }^{2-15}$ Adsorption to terrace sites with $\mathrm{CN}=8$ or 9 does not occur. ${ }^{16} \mathrm{CO}$ adsorption studies also display a number of coverage-dependent results. For example, quantification of the coverage with $\mathrm{CO}$ pressure (or with temperature) reveals coverage-dependent, non-Langmuir behavior. ${ }^{17-21}$ The adsorption enthalpy shows a coveragedependence, decreasing with increasing coverage. ${ }^{17-24}$ Also, the infrared studies reveal a common $\mathrm{CO}$ peak that typically red shifts with increasing coverage. ${ }^{25-28}$

To account for the physicochemical, coverage-dependent behavior of $\mathrm{CO}$ adsorption on gold, we developed a treatment of the Temkin adsorption model. ${ }^{29}$ This thermodynamic model is an extension of the Langmuir adsorption model that incorporates a linear variation in binding energy with coverage, and has three cases that are similar but not equivalent. The adsorbate interaction case takes into account direct adsorbateadsorbate interactions or indirect adsorbate-substrate interactions. This case assumes that these interactions produce a linear variation of adsorption enthalpy with adsorbate coverage. In contrast, the heterogeneous surface case assumes a uniform distribution of heterogeneous binding sites. It is assumed that the adsorption enthalpy varies linearly over these different binding sites. The third case involves a common approximation for midrange adsorbate coverage. According to this approximation, the expressions for the adsorbate interaction and the heterogeneous surface cases are simplified, producing a new common expression. This common expression is the familiar Temkin isothermal result; coverage varies with the logarithm of pressure.

Previously, we demonstrated that this treatment of the Temkin adsorption model provides meaningful thermodynamic metrics for enthalpy and entropy, which can be used to characterize and explain differences between various catalysts. ${ }^{29}$ The model is straightforward and applicable for fitting both isothermal and isobaric data sets.

Received: March 8, 2012

Revised: $\quad$ May 1, 2012

Published: May 1, 2012 
We now report the results of new $\mathrm{CO}$ adsorption studies on the real-world catalysts $\mathrm{Au} / \mathrm{TiO}_{2}, \mathrm{Au} / \mathrm{Fe}_{2} \mathrm{O}_{3}$, and $\mathrm{Au} / \mathrm{ZrO}_{2}$. Infrared transmission spectroscopy was used for quantitatively measuring the adsorption coverage under isobaric experimental conditions. The coverage as a function of temperature was fit with the Temkin adsorption model that was previously developed. ${ }^{29}$ The resulting thermodynamic adsorption metrics (cf., the adsorption enthalpy at zero and full coverage, and the adsorption entropy) are in excellent agreement with previously reported values. Further validation of this new Temkin treatment was also achieved by fitting literature data for $\mathrm{CO}$ adsorption on another real-world $\mathrm{Au} / \mathrm{TiO}_{2}$ catalyst, and on two model $\mathrm{Au} / \mathrm{TiO}_{2}$ catalysts. The data are very well represented by the Temkin adsorbate interaction model. The resulting adsorption enthalpy at zero coverage shows a nearly linear trend with $\mathrm{Au}$ particle size. This trend appears to be correlated with the abundance of low-coordinate Au sites (cf., $\mathrm{CN}=6$ and 7 for corners and edges, respectively).

\section{TEMKIN ADSORPTION MODEL}

Because the Temkin adsorption model with its three cases was previously developed in detail, only a brief review of the important expressions will be presented. ${ }^{29}$ The Temkin model is an extension of the Langmuir model that incorporates a linear variation of the adsorption energy. ${ }^{30,31}$ The relevant Langmuir expressions are:

$$
\begin{aligned}
& \theta=\frac{K_{\mathrm{T}} P}{1+K_{\mathrm{T}} P} \\
& \frac{P}{S}=\frac{1}{K_{\mathrm{T}} S_{\max }}+\frac{P}{S_{\max }}
\end{aligned}
$$

where $\theta$ is the normalized coverage, $K_{\mathrm{T}}$ is the binding constant, $P$ is the equilibrium pressure, $S$ is the measured coverage at $P$, and $S_{\max }$ is the maximum coverage. Equation 2 is the linear form of the Langmuir isotherm and is used to determine $S_{\max }$ for normalizing the coverage (cf., $\theta=S / S_{\max }=0-1$ ).

The Temkin adsorbate interaction case assumes (i) a uniform distribution of equivalent binding sites, and (ii) the binding enthalpy on all of the sites varies linearly with coverage due to adsorbate interactions. The surface is uniform, meaning that all binding sites are equivalent with the same intrinsic binding energy in the absence of adsorbate interactions. The interactions can be direct adsorbate-adsorbate interactions involving the coupling of adsorbate dipoles (also called dipoledipole coupling, or dynamic interaction) or indirect adsorbatesubstrate interactions involving electronic interaction with the binding surface (also called chemical interaction). The coverage $\theta$ has the same meaning as in the Langmuir model, but $K_{\mathrm{T}}$ is allowed to vary with coverage due to a linear change in $\Delta H$ with coverage, according to:

$$
\Delta H_{\theta}=\Delta H_{0}-\theta \delta \Delta H \quad \text { where } \quad \delta \Delta H=\Delta H_{0}-\Delta H_{1}
$$

All enthalpy terms are negative, $\Delta H_{0}$ and $\Delta H_{1}$ are the enthalpies at zero and full coverage, and $\theta$ goes from 0 to 1 . The relevant coverage-dependent expressions for the Temkin adsorbate interaction case are then:

$$
\Delta G_{\theta, T}=\Delta H_{0}-\theta \delta \Delta H-T \Delta S
$$

$$
\begin{aligned}
& \Delta G_{\theta, T}=-R T \ln \left(\frac{\theta}{P(1-\theta)}\right) \\
& -R T \ln \left(\frac{\theta}{P(1-\theta)}\right)=\Delta H_{0}-\theta \delta \Delta H-T \Delta S
\end{aligned}
$$

where $\Delta G_{\theta, T}$ can be experimentally determined at each $(\theta, T$, $P$ ) according to eq 5 . The combination of the two $\Delta G_{\theta, T}$ expressions (eqs 4 and 5) yields eq 6, from which one can derive expressions for fitting isothermal experimental data (in terms of $P_{\theta, T}$ ) and isobaric experimental data (in terms $T_{\theta, P}$ ). An expression in terms of coverage $\theta_{P, T}$ is not possible. The three fitting parameters or metrics are $\Delta H_{0}, \delta \Delta H$, and $\Delta S$. It is generally assumed that these thermodynamic parameters are independent of coverage and temperature. With the proper collection of experimental data (i.e., with variable $(P, T, \theta)$ data sets), one can uniquely determine these three metrics. Again, $\Delta H_{0}$ is the adsorption enthalpy (negative value) at zero coverage, $\delta \Delta H$ is the difference in enthalpy (negative value) between zero and full coverage, and $\Delta S$ is the adsorption entropy (negative value).

In contrast, the Temkin heterogeneous surface case assumes (i) a uniform distribution of heterogeneous binding sites, and (ii) the binding energy on each site (or type of site) varies linearly over all sites. Uniform distribution means that the surface is divided into a number of uniform elements $\mathrm{d} s$ and the coverage on any particular surface element $s$ (with binding energy $\Delta H_{\mathrm{s}}$ ) obeys the Langmuir and associated thermodynamic expressions:

$$
\begin{aligned}
& \theta_{s}=\frac{K_{s} P}{1+K_{s} P} \\
& K_{s}=e^{-\Delta G_{s} / R T} \\
& \Delta G_{s}=\Delta H_{s}-T \Delta S
\end{aligned}
$$

The linear decrease in the adsorption enthalpy due to surface heterogeneity is expressed as:

$$
\Delta H_{s}=\Delta H_{0}-s \delta \Delta H
$$

In this case, $\Delta H_{0}$ is the largest adsorption enthalpy for the $s=0$ surface element and $\Delta H_{1}$ is the smallest enthalpy for the $s=1$ element, $\delta \Delta H$ is the difference between the two extreme values, and $s$ ranges from 0 to 1 (i.e., the total number of surface elements is normalized to unity). As an example, consider a heterogeneous surface divided into five elements with $s=0$, $0.25,0.50,0.75$, and 1 , and with binding energies that vary linearly as $\Delta H_{0}=-65, \Delta H_{0.25}=-62.5, \Delta H_{0.5}=-60, \Delta H_{0.75}=$ -57.5 , and $\Delta H_{1}=-55 \mathrm{~kJ} / \mathrm{mol}$. At a particular pressure, the coverage on each surface element is given by eq 7 . It is important to note that $s$ is simply an index, $s \neq \theta$, and eqs 10 and 3 are not equivalent.

The observed experimental coverage (i.e., the total coverage on all surface elements) is:

$$
\begin{aligned}
\theta & =\int_{0}^{1} \theta_{s} \mathrm{~d} s \\
& =\int_{0}^{1} \frac{K_{s} P}{1+K_{s} P} \mathrm{~d} s
\end{aligned}
$$

Integration gives: 


$$
\theta=-\frac{R T}{\delta \Delta H} \ln \left(\frac{1+K_{0} P}{1+K_{1} P}\right)
$$

where $K_{0}$ is the binding constant for the strongest surface element, and $K_{1}$ is the constant for the weakest element, as given by eqs 8 and 9 . The negative sign in eq 12 is typically incorporated into the value of $\delta \Delta H$, such that $-\delta \Delta H$ is presented as positive. Unlike the adsorbate interaction case above, this case provides an expression (cf., eq 12) in terms of coverage $\theta_{P, T}$. The fitting parameters or metrics are still $\Delta H_{0}$, $\delta \Delta H$, and $\Delta S$, and it is generally assumed that these thermodynamic parameters are independent of coverage and temperature. With the proper collection of experimental data (i.e., with variable $(P, T, \theta)$ data sets), one can uniquely determine these three metrics.

The Temkin midrange approximation results from a simplification of the expressions for the other two cases. For the adsorbate interaction case, a common approximation is made near $\theta=0.5$, such that the logarithm term containing the coverage in eq 6 is approximated as zero, cf.:

$$
\ln \left(\frac{\theta}{(1-\theta)}\right) \approx 0
$$

This leads to the following simplified expression:

$$
\theta=-\frac{\left(R T \ln P-\Delta H_{0}+T \Delta S\right)}{\delta \Delta H}
$$

The negative sign is typically incorporated into the value of $\delta \Delta H$, such that $-\delta \Delta H$ is presented as positive. Similarly, for the heterogeneous surface case, the approximation is made that for midrange coverage the pressure is sufficiently large such that $K_{0} P$ is much greater than 1 , while $K_{1} P$ is much less than 1 . Equation 12 then reduces to eq 14 .

Historically, this midrange approximation expression has been utilized to demonstrate that for many systems the adsorbate surface coverage varies with the logarithm of pressure. The claim can then be made that the adsorption process follows or obeys the Temkin adsorption model, and that the adsorption enthalpy (or binding energy) varies linearly with coverage (or binding site heterogeneity). However, it appears that what is not appreciated is the fact that the enthalpy or energy terms determined from this approximation always lead to a systematic error in the determined values. ${ }^{29}$

As we have previously discussed in detail, the Temkin adsorbate interaction case is the most appropriate case to use for describing and fitting data for the adsorption of $\mathrm{CO}$ on gold. $^{29}$ It is important to note that nearly all gold particles and surfaces (for both real-world and model catalysts) exhibit very similar CO adsorption behavior. This includes a number of coverage-dependent observations that would be consistent with the Temkin adsorbate interaction model. Studies almost universally indicate that $\mathrm{CO}$ adsorption on gold involves lowcoordinate sites. $^{2-15}$ These are typically understood to be of a limited number of $\mathrm{CN}=6$ and 7 sites, corresponding to corners (or kinks) and edges (or steps), respectively. As we previously demonstrated, the adsorbate interaction case would be appropriate for a limited number of binding sites with similar energies, and it can account for coverage-dependent behavior. ${ }^{29}$ Furthermore, we believe that the adsorbate interaction case involving indirect interaction of $\mathrm{CO}$ with gold particles (or gold metal surfaces) most accurately describes the physicochemical behavior of the adsorption process and is the best explanation for the collection of experimental results. ${ }^{29}$ Accordingly, $\Delta H_{0}$ represents the intrinsic $\mathrm{CO}$ adsorption enthalpy without adsorbate interactions, while $\delta \Delta H$ is a measure of how the adsorption enthalpy changes with $\mathrm{CO}$ coverage and is attributed to adsorbate-substrate electronic interactions between $\mathrm{CO}$ and the $\mathrm{Au}$ nanoparticles.

Concerning the Temkin heterogeneous surface case, because it assumes a uniform distribution of heterogeneous binding sites, this case does not seem appropriate for nanoparticle catalysts. The Temkin adsorbate interaction model is therefore used below for fitting the $\mathrm{CO}$ adsorption on supported gold nanoparticle catalysts.

\section{EXPERIMENTAL SECTION}

The World Gold Council (WGC) provided the $1.51 \% \mathrm{Au} /$ $\mathrm{TiO}_{2}$ and the $4.48 \% \mathrm{Au} / \mathrm{Fe}_{2} \mathrm{O}_{3}$ catalysts. According to the WGC data sheets, the gold particle sizes were $d=3.8 \pm 0.8 \mathrm{~nm}$ for $\mathrm{Au} / \mathrm{TiO}_{2}$ and $d=3.7 \pm 0.9 \mathrm{~nm}$ for $\mathrm{Au} / \mathrm{Fe}_{2} \mathrm{O}_{3}$ as determined by TEM. The $1.92 \% \mathrm{Au} / \mathrm{ZrO}_{2}$ catalyst $(d=1.6 \pm 0.6 \mathrm{~nm}$ by TEM) was prepared by the deposition-precipitation method. First, the support was precipitated from $\mathrm{ZrOCl}_{2} \cdot 8 \mathrm{H}_{2} \mathrm{O}$ (Fluka) at a constant $\mathrm{pH}$ of 8.6, aged under reflux conditions for $20 \mathrm{~h}$, washed free of chloride $\left(\mathrm{AgNO}_{3}\right.$ test $)$, and then dried at $383 \mathrm{~K}$ overnight. The support was then calcined by heating to $923 \mathrm{~K}$ in flowing air for $6 \mathrm{~h}$, followed by cooling to room temperature. Gold was deposited on the calcined support at constant $\mathrm{pH}$ (0.5 $\mathrm{M} \mathrm{NaOH}$ aqueous solution, $\mathrm{pH}=8.6)$, filtered, and then dried at $310 \mathrm{~K}$ for $15 \mathrm{~h}$.

Each catalyst was pressed into a self-supporting pellet and mounted in a cell that allowed thermal treatment in a controlled atmosphere. Pellet samples were pretreated in situ by reduction in hydrogen gas at $523 \mathrm{~K}$ (for $\mathrm{Au} / \mathrm{TiO}_{2}$ and $\mathrm{Au} /$ $\mathrm{Fe}_{2} \mathrm{O}_{3}$ ) or at $423 \mathrm{~K}$ (for $\mathrm{Au} / \mathrm{ZrO}_{2}$ ), followed by hydration at 298 K. FTIR transmission spectra were collected with a PerkinElmer 1760 spectrometer equipped with an MCT detector. A background spectrum (collected before exposure of $\mathrm{CO}$ ) was subtracted from each sample spectrum. The catalyst samples were cooled with liquid nitrogen and then exposed to a constant pressure of $\mathrm{CO}$ according to the following conditions: $\mathrm{Au} / \mathrm{TiO}_{2}$ at $77 \mathrm{~K}$ and $P_{\mathrm{CO}}=3 \mathrm{mbar} ; \mathrm{Au} / \mathrm{Fe}_{2} \mathrm{O}_{3}$ at $103 \mathrm{~K}$ and $P_{\mathrm{CO}}=0.7 \mathrm{mbar} ; \mathrm{Au} / \mathrm{ZrO}_{2}$ at $90 \mathrm{~K}$ and $P_{\mathrm{CO}}=0.5 \mathrm{mbar}$. Spectra were then collected as the samples were allowed to gradually warm to room temperature. All spectra were normalized to the gold content in each pellet before integration of the $\mathrm{CO}$ band. The infrared integrated intensities around $2100 \mathrm{~cm}^{-1}$ were then used to measure the $\mathrm{CO}$ adsorption $(S)$ at each temperature, while the spectra at the lowest temperature were used to determine the maximum $\mathrm{CO}$ adsorption $\left(S_{\max }\right)$. The $\mathrm{CO}$ adsorption coverage was then defined as $\theta=S / S_{\max }$.

\section{RESULTS}

Infrared transmission spectra were collected and quantified for the isobaric adsorption of $\mathrm{CO}$ on the gold catalysts $\mathrm{Au} / \mathrm{TiO}_{2}$, $\mathrm{Au} / \mathrm{Fe}_{2} \mathrm{O}_{3}$, and $\mathrm{Au} / \mathrm{ZrO}_{2}$. Illustrative spectra for adsorption on the $\mathrm{Au} / \mathrm{ZrO}_{2}$ catalyst are displayed in Figure 1. The $\mathrm{CO}$ pressure was held constant at $0.5 \mathrm{mbar}$, while the temperature was gradually warmed from $90 \mathrm{~K}$. The integrated peak area (around $2100 \mathrm{~cm}^{-1}$ ) at $90 \mathrm{~K}$ was used to define the maximum coverage and to normalize the coverage at the higher temperatures. The spectra displayed in Figure 1 are for temperatures from 190 to $277 \mathrm{~K}$, corresponding to $\mathrm{CO}$ coverage of $\theta=0.84-0.45$, respectively. Spectra with similar 


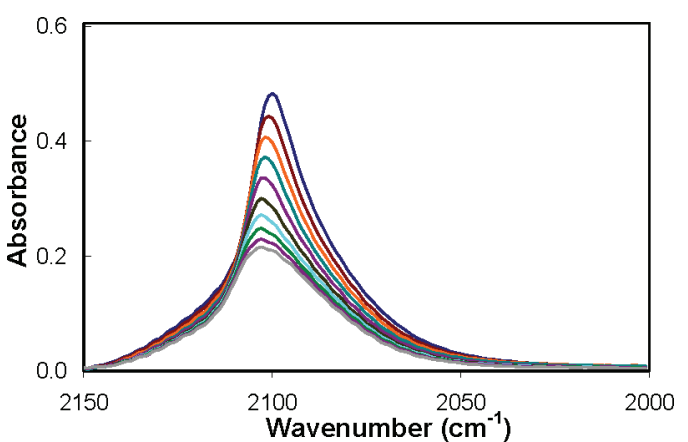

Figure 1. Isobaric infrared transmission spectra of $\mathrm{CO}$ adsorption on the $\mathrm{Au} / \mathrm{ZrO}_{2}$ catalyst. The temperature was gradually increased from $190 \mathrm{~K}$ (largest peak) to $277 \mathrm{~K}$ (smallest peak), while the CO pressure was held constant at $0.5 \mathrm{mbar}$. The integrated peak area represents the $\mathrm{CO}$ coverage at each temperature.

characteristics were collected and quantified for $\mathrm{CO}$ adsorption on $\mathrm{Au} / \mathrm{TiO}_{2}$ and on $\mathrm{Au} / \mathrm{Fe}_{2} \mathrm{O}_{3}$, but are not shown for brevity.

The isobaric plot of coverage as a function of temperature is shown in Figure 2a, again for $\mathrm{CO}$ adsorption on $\mathrm{Au} / \mathrm{ZrO}_{2}$ (the data from the spectra in Figure 1). Also in Figure 2, the adsorption data have been plotted according to the complete Temkin adsorbate interaction treatment. $\Delta G$ was calculated for each coverage-temperature data point using eq 5. Plots of $\Delta G$ versus temperature and $\Delta G$ versus coverage were then prepared. The data for these three plots were fit simultaneously using eqs 4-6 and the three thermodynamic fitting metrics $\Delta H_{0}, \delta \Delta H$, and $\Delta S$. Because the data for only one isobar were analyzed, the adsorption entropy was fixed to the value determined previously for $\mathrm{CO}$ adsorption on an $\mathrm{Au} / \mathrm{TiO}_{2}$ catalyst (cf., $\Delta S=-142 \mathrm{~J} / \mathrm{K} \cdot \mathrm{mol}){ }^{29}$ Excellent fits were then achieved with the values $\Delta H_{0}=-75.3 \mathrm{~kJ} / \mathrm{mol}$ and $\delta \Delta H=$ $-39.5 \mathrm{~kJ} / \mathrm{mol}$.

The same procedure was utilized for analyzing the data for the other two catalysts. The resulting thermodynamic parameters are listed in Table 1 . The $\Delta H_{0}$ values for these two catalysts are very similar (cf., $\Delta H_{0}=-63.4$ and $-66.0 \mathrm{~kJ} /$ mol for $\mathrm{Au} / \mathrm{Fe}_{2} \mathrm{O}_{3}$ and $\mathrm{Au} / \mathrm{TiO}_{2}$, respectively), with the $\mathrm{Au} /$ $\mathrm{TiO}_{2}$ showing only slightly stronger intrinsic $\mathrm{CO}$ binding. Although their underlying supports are different, these two catalysts have essentially the same Au particle size (cf., $d=3.7-$ $3.8 \mathrm{~nm}$ ), which appears to be the most important parameter for controlling the intrinsic binding energy $\Delta H_{0}$. Thus, comparing these two catalysts to the $\mathrm{Au} / \mathrm{ZrO}_{2}$ catalyst, there is a clear difference due to the smaller $\mathrm{Au}$ particle size (cf., $d=1.6 \mathrm{~nm}$ ) and not to the different supports, as we discuss further below.

\section{APPLICATION OF THE TEMKIN ADSORBATE INTERACTION MODEL}

a. Real-World $\mathrm{Au} / \mathrm{TiO}_{2}$ Catalyst. To further validate the applicability of the Temkin adsorbate interaction model, the $\mathrm{CO}$ adsorption data from a study involving supported gold nanoparticles of a $\mathrm{Au} / \mathrm{TiO}_{2}$ real-world catalyst by Bianchi's research group were analyzed. ${ }^{22}$ Particle size was reported to be in the typical range for the deposition-precipitation method, ca. $d=3-5 \mathrm{~nm}$. Infrared spectroscopy (AEIR: absorption equilibrium infrared) was used to quantify the $\mathrm{CO}$ adsorption coverage. Two isobars at $P=1$ and $10 \mathrm{kPa}$ over a temperature range of $T \approx 300-400 \mathrm{~K}$ were reported in Figure 4 of ref 22 .

These two isobars are reproduced in Figure 3, along with plots for the analysis using the Temkin adsorbate interaction
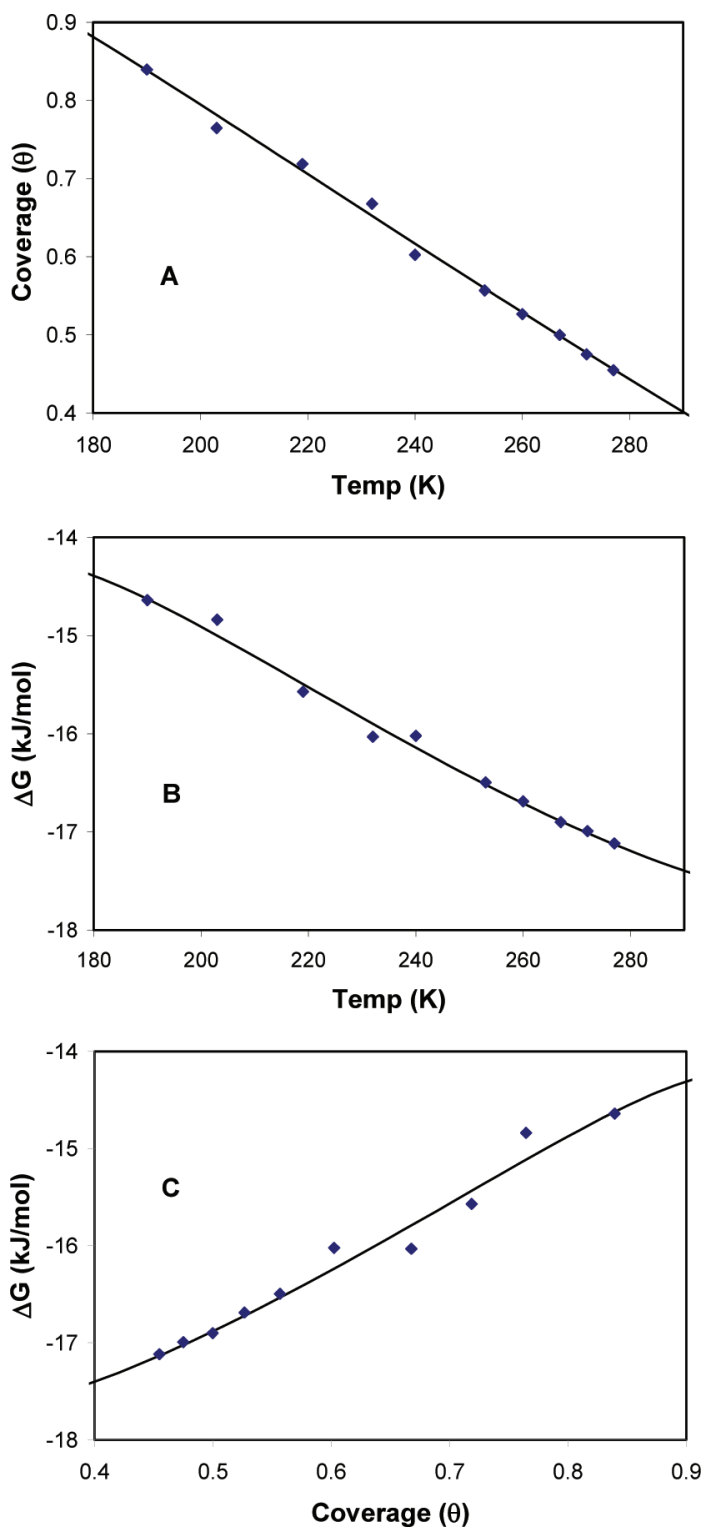

Figure 2. Thermodynamic plots of the isobaric data for $\mathrm{CO}$ adsorption on the $\mathrm{Au} / \mathrm{ZrO}_{2}$ catalyst for $P=0.5$ mbar. $\Delta G$ was calculated for each $(\theta, T)$ point in $(\mathrm{A})$ according to the Temkin adsorbate interaction expression, eq 5 . The curves through the data are the fits for the Temkin adsorbate interaction case, see eqs $4-6$, with fitting parameters $\Delta H_{0}=-75.3 \mathrm{~kJ} / \mathrm{mol}, \delta \Delta H=-39.5 \mathrm{~kJ} / \mathrm{mol}$, and $\Delta S=$ $-142 \mathrm{~J} / \mathrm{K} \cdot \mathrm{mol}$.

model. For completeness, a full treatment of the Temkin adsorbate interaction model was used to determine the best set of thermodynamic metrics. $\Delta G$ was calculated for each coverage-temperature point using eq 5 . The entropy value was set at the value (cf., $\Delta S=-142 \mathrm{~J} / \mathrm{K} \cdot \mathrm{mol}$ ) determined from the analysis of multiple isotherms, as discussed previously. ${ }^{29}$ The fitting of the three plots ( $\theta$ vs $T, \Delta G$ vs $T$, and $\Delta G$ vs $\theta$ ) was performed simultaneously with one set of thermodynamic metrics for both pressures (i.e., a total of six curves fit simultaneously). The resulting curves from this fitting procedure are displayed in Figure 3. Taking into account the scatter in the experimental data points, the fits are excellent. The thermodynamic metrics determined from the Temkin model for this data set are given in Table 1 (cf., $\Delta H_{0}=-69.3$ and $\delta \Delta H=-12.2 \mathrm{~kJ} / \mathrm{mol}$ ). 
Table 1. Thermodynamic Fitting Metrics Determined for the Temkin Adsorbate Interaction Model As Applied to CO Adsorption Data Sets ${ }^{a}$

\begin{tabular}{|c|c|c|c|c|}
\hline \multicolumn{2}{|c|}{ system studied ( $d$ in $\mathrm{nm}$ ) } & $\Delta H_{0}$ & $\delta \Delta H$ & $\Delta S^{b}$ \\
\hline \multicolumn{5}{|l|}{ This Work } \\
\hline $\mathrm{Au} / \mathrm{ZrO}_{2}$ & $d=1.6$ & 75.3 & 39.5 & 142 \\
\hline $\mathrm{Au} / \mathrm{Fe}_{2} \mathrm{O}_{3}$ & $d=3.7$ & 63.4 & 31.0 & 142 \\
\hline $\mathrm{Au} / \mathrm{TiO}_{2}$ & $d=3.8$ & 66.0 & 35.0 & 142 \\
\hline \multicolumn{5}{|c|}{ Real-World Catalyst ${ }^{22}$} \\
\hline $\mathrm{Au} / \mathrm{TiO}_{2}$ & $d=3$ & $69.3(74)$ & $12.2(27)$ & $142(-)$ \\
\hline \multicolumn{5}{|c|}{ Model $\mathrm{Au} / \mathrm{TiO}_{2}$ Catalysts $\mathrm{I}^{21}$} \\
\hline (i) & $d=3.1$ & $64.0(52.3)$ & $22.0(28.0)^{c}$ & $120(-)$ \\
\hline (ii) & $d=2.5$ & $66.0(76.1)$ & $17.0(16.0)^{c}$ & $140(-)$ \\
\hline (iii) & $d=1.8$ & $74.0(68.2)$ & $23.0(0)^{c}$ & $160(-)$ \\
\hline \multicolumn{5}{|c|}{ Model Au/TiO ${ }_{2}$ Catalysts $\mathrm{II}^{23}$} \\
\hline (i) & $d=4$ & $64.7(62)$ & $7.0(18)$ & $142(-)$ \\
\hline (ii) & $d=3$ & $67.6(66)$ & $11.0(24)$ & $142(-)$ \\
\hline (iii) & $d=2$ & $74.7(74)$ & $23.0(34)$ & $142(-)$ \\
\hline
\end{tabular}

${ }^{a}$ Enthalpy values are listed as $(-) \mathrm{kJ} / \mathrm{mol}$, while entropies are $(-) \mathrm{J} /$ $\mathrm{K} \cdot \mathrm{mol}$. Literature values are given in italicized parentheses. ${ }^{b}$ Because only one pressure was used in all of the studies (except for those of ref 21 ), it was not possible to uniquely determine the entropy. For fitting of these data sets, the entropy was set to the value determined from the fit of multiple isotherms for $\mathrm{CO}$ on $1 \% \mathrm{Au} / \mathrm{TiO}_{2}$ catalysts reported previously. ${ }^{29}{ }^{c}$ These are approximate values based upon the data sets in Figures 5, 9, and 12 of ref 21; see text for details.

The original authors analyzed the data using a form of the Temkin heterogeneous surface model (cf., eq 12) with the use of binding coefficient expressions $\left(K_{0}\right.$ and $\left.K_{1}\right)$ derived from statistical thermodynamics, thereby removing the entropy term and reducing the fitting to just two parameters. From their analysis, they reported energy values for the strongest and weakest binding sites of $E_{0}=-74$ and $E_{1}=-47 \mathrm{~kJ} / \mathrm{mol}$, respectively. Using their Temkin heterogeneous surface expression, we were also able to reproduce their reported adsorption energies (cf., $E_{0}=-73 \mathrm{~kJ} / \mathrm{mol}$ and $E_{1}=-48 \mathrm{~kJ} /$ mol). Additionally, we used our heterogeneous surface expression (cf., eq 12) to fit this data set. Holding $\Delta S$ constant (cf., $-142 \mathrm{~J} / \mathrm{K} \cdot \mathrm{mol}$ ), our Temkin heterogeneous case yielded enthalpy values (ca., $\Delta H_{0}=-75.0$ and $\Delta H_{1}=-51.6 \mathrm{~kJ} / \mathrm{mol}$, respectively) that agree with the results using Bianchi's expression that utilizes statistical thermodynamic relationships for the binding coefficients. As we have previously demonstrated, the Temkin heterogeneous surface case always yields larger $\Delta H_{0}$ and $\delta \Delta H$ values as compared to the Temkin adsorbate interaction case. ${ }^{29}$ The heterogeneous surface case also requires a uniform distribution of heterogeneous sites, which is rather unlikely for real nanoparticle catalysts. Furthermore, as we have previously discussed in detail, the adsorbate interaction case is most consistent with the current body of experimental and theoretical evidence. ${ }^{29}$

b. Model Au/ $/ \mathrm{TiO}_{2}$ Catalysts I. Meier and Goodman reported a surface science study for $\mathrm{CO}$ adsorption on $\mathrm{Au}$ clusters supported on a crystalline $\mathrm{TiO}_{2}$ surface, which we describe as model $\mathrm{Au} / \mathrm{TiO}_{2}$ catalysts. ${ }^{21}$ By varying the deposition of gold, measured as $\mathrm{Au}$ monolayer equivalent (MLE), they prepared Au clusters of various sizes, cf., $d=1.8$, 2.5 , and $3.1 \mathrm{~nm}$. Infrared reflection absorption spectroscopy (IRAS) was used to quantify the adsorption coverage, and the pressure and temperature ranges were $P=10^{-2}-10^{-8}$ Torr and $T=130-265 \mathrm{~K}$. Because the data showed a coveragedependent binding enthalpy, a Clausius-Clapeyron analysis of
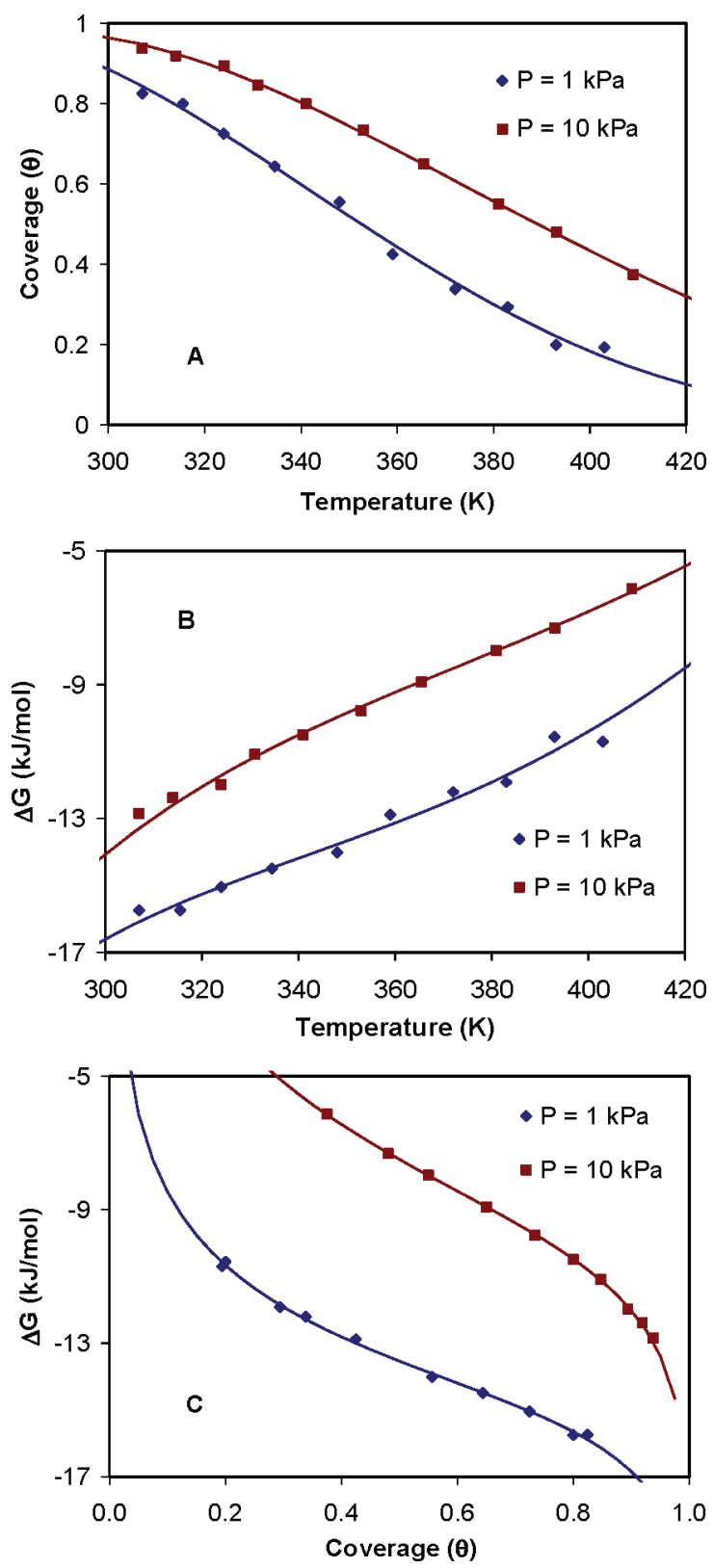

Figure 3. Application of the Temkin adsorbate interaction model to the $\mathrm{CO}$ adsorption on $\mathrm{Au} / \mathrm{TiO}_{2}$ catalysts from ref 22. The isobaric coverage data (A) comes from adsorption equilibrium infrared spectra. $\Delta G$ was calculated for each $(\theta, T)$ point in (A) according to the Temkin adsorbate interaction expression, eq 5 . The curves in (A)-(C) are from the fitting of all of the data to one set of thermodynamic metrics $\left(\Delta H_{0}, \delta \Delta H\right.$, and $\left.\Delta S\right)$ according to the Temkin adsorbate interaction model. See Table 1 for all fitting values.

isosteres (i.e., constant coverage) was utilized to determine enthalpies.

From the reported isotherms (Figures 3, 7, and 11 from ref 21 ), we extracted isobaric data sets for two pressures for each cluster size. This was the most effective way of using as much of the original data to cover the largest range of $\mathrm{CO}$ coverage. Regarding the normalization of the coverage, for the $d=3.1 \mathrm{~nm}$ data, the coverage is as reported by the authors. For the other two particle sizes, the data sets were normalized using the lowest temperature and highest pressures to determine an $S_{\max }$ according to eq 2 . 
Plots of the normalized data and fits from the Temkin adsorbate interaction model are shown in Figure 4. Cluster size
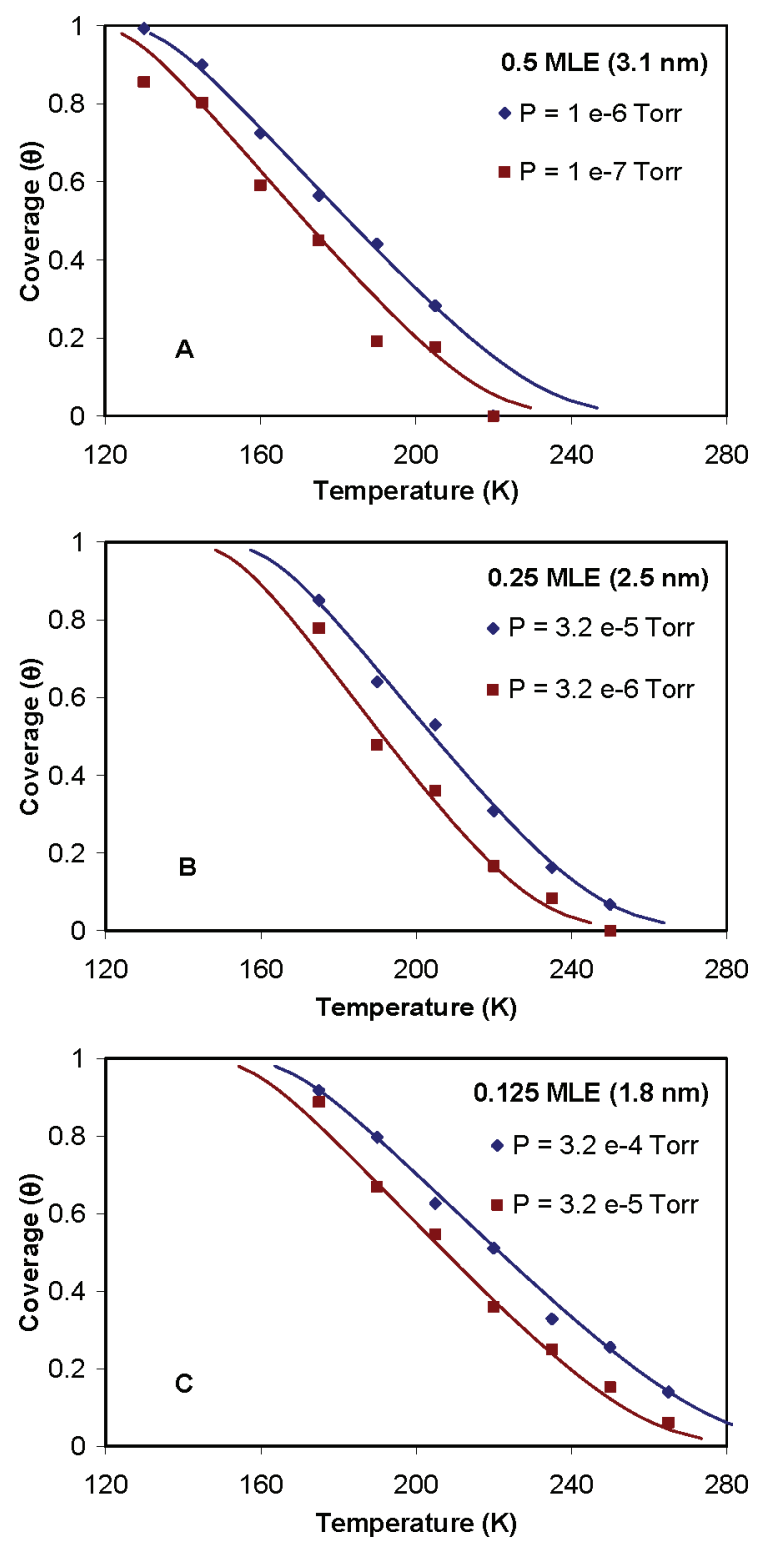

Figure 4. Application of the Temkin adsorbate interaction model to $\mathrm{CO}$ adsorption data on $\mathrm{Au} / \mathrm{TiO}_{2}$ model catalysts I from ref 21 . The $\mathrm{Au}$ particle size is reported as monolayer equivalent gold (MLE) and as average diameter $(\mathrm{nm})$. The coverage data come from infrared reflection absorption spectra. For each particle size, two pressures were selected to span the largest coverage range; see the text for details. The curves are from the fitting of each particle size to one set of thermodynamic metrics $\left(\Delta H_{0}, \delta \Delta H\right.$, and $\left.\Delta S\right)$; see Table 1 for values.

and pressures are given in the figure (note that the two pressures differ by an order of magnitude). The two isobars for each Au cluster size were fit simultaneously using the same set of thermodynamic metrics, thereby yielding unique entropy values. The value of the entropy term affects the separation of the two isobars for each cluster size.

The resulting thermodynamic metrics for the Temkin adsorbate interaction model are given in Table 1. The enthalpy at zero coverage varies with cluster size as $-\Delta H_{0}=64.0,66.0$, and $74.0 \mathrm{~kJ} / \mathrm{mol}$ for $d=3.1,2.5$, and $1.8 \mathrm{~nm}$, respectively. These values can be compared to the values reported by the authors (from a Clausius-Clapeyron analysis of isosteres) as $-\Delta H_{0}=52.3 \pm 2.9,76.1 \pm 4.5$, and $68.2 \pm 4.5 \mathrm{~kJ} / \mathrm{mol}$, respectively. The errors reported here have been extracted from Figure 13 of ref 21 . The agreement in the range of values is pretty good, especially in light of the scatter in the original data and the large error bars. In contrast to a jump in $\Delta H_{0}$ at $d=2.5$ $\mathrm{nm}$ reported by the authors (cf., $\Delta H_{0}=-76.1 \mathrm{~kJ} / \mathrm{mol}$ ), the results from the Temkin model gives rise to a linear relationship between $\Delta H_{0}$ and Au cluster size. This linear trend seems reasonable and agrees with the results from another $\mathrm{Au} / \mathrm{TiO}_{2}$ model catalysts study that also displays a trend in $\Delta H_{0}$ with particle size; see below. ${ }^{23}$ Table 1 contains the values for $\delta \Delta H$, which are all very similar and do not show a trend with cluster size. These values can be compared to the literature values that have been estimated from data in Figures 5, 9, and 12 of ref 21 . It is interesting to note that the literature value of $\delta \Delta H=0 \mathrm{~kJ} /$ mol for the $d=1.8 \mathrm{~nm} \mathrm{Au}$ clusters would suggest that the adsorption data should fit a Langmuir expression. However, the data cannot be fit using the Langmuir expression. Instead, the Temkin adsorbate interaction model with an enthalpy that varies with coverage accurately represents this data. Last, while the original analysis did not yield an adsorption entropy, this Temkin treatment yields entropy values of $-\Delta S=120,140$, and $160 \mathrm{~J} / \mathrm{K} \cdot \mathrm{mol}$ for $d=3.1,2.5$, and $1.8 \mathrm{~nm}$, respectively. Thus, there is an interesting and somewhat expected trend in $\Delta S$ with $\Delta H_{0}$. As the particles become smaller and the binding becomes stronger, the adsorption entropy increases in magnitude, indicating that as the $\mathrm{CO}$ is more tightly bound it therefore has less entropy.

c. Model Au/ $/ \mathrm{TiO}_{2}$ Catalysts II. Another surface science study on $\mathrm{Au} / \mathrm{TiO}_{2}$ model catalysts was reported by Behm's research group. ${ }^{23} \mathrm{By}$ varying the amount of deposited $\mathrm{Au}$, they generated particles of different size, cf., $d=2,3$, and $4 \mathrm{~nm}$. The $\mathrm{CO}$ adsorption coverage was quantified using infrared spectroscopy, in this case, polarization-modulation infrared reflection-absorption spectroscopy (PM-IRAS). The pressure of $\mathrm{CO}$ was held constant at $10 \mathrm{mbar}$, and the temperature was varied, $T=300-400 \mathrm{~K}$. Isobars for the three sizes were reported in Figures 1 and 2 of ref 23. The authors determined binding enthalpies based upon the Temkin treatment developed by Bianchi. ${ }^{22}$ Again, this treatment is equivalent to the heterogeneous surface case, eq 12 , with the use of binding coefficient expressions $\left(K_{0}\right.$ and $\left.K_{1}\right)$ derived from statistical thermodynamics. The authors reported binding energies that decrease in magnitude with increasing Au particle size.

The isobars for this data set are reproduced in Figure 5, along with plots for the analysis using the Temkin adsorbate interaction model. Because only one pressure for each particle size was reported, we used a full treatment of the Temkin adsorbate interaction model to determine the best set of thermodynamic metrics. In other words, the fitting for the three plots of $\theta$ versus $T, \Delta G$ versus $T$, and $\Delta G$ versus $\theta$ was performed simultaneously with one set of thermodynamic parameters for each particle size. $\Delta G$ was calculated for each coverage-temperature point using eq 5 . The curves in Figure 5 are from this fitting procedure. The fits are very good, particularly considering the scatter in the original data points.

The thermodynamic metrics based upon this fitting are reported in Table 1. Because there is only one data set for each particle size, a unique value of the adsorption entropy cannot be determined. We therefore used $\Delta S=-142 \mathrm{~J} / \mathrm{K} \cdot \mathrm{mol}$, as determined previously from multiple isotherms. ${ }^{29}$ For comparison purposes, Table 1 also includes the values reported by 

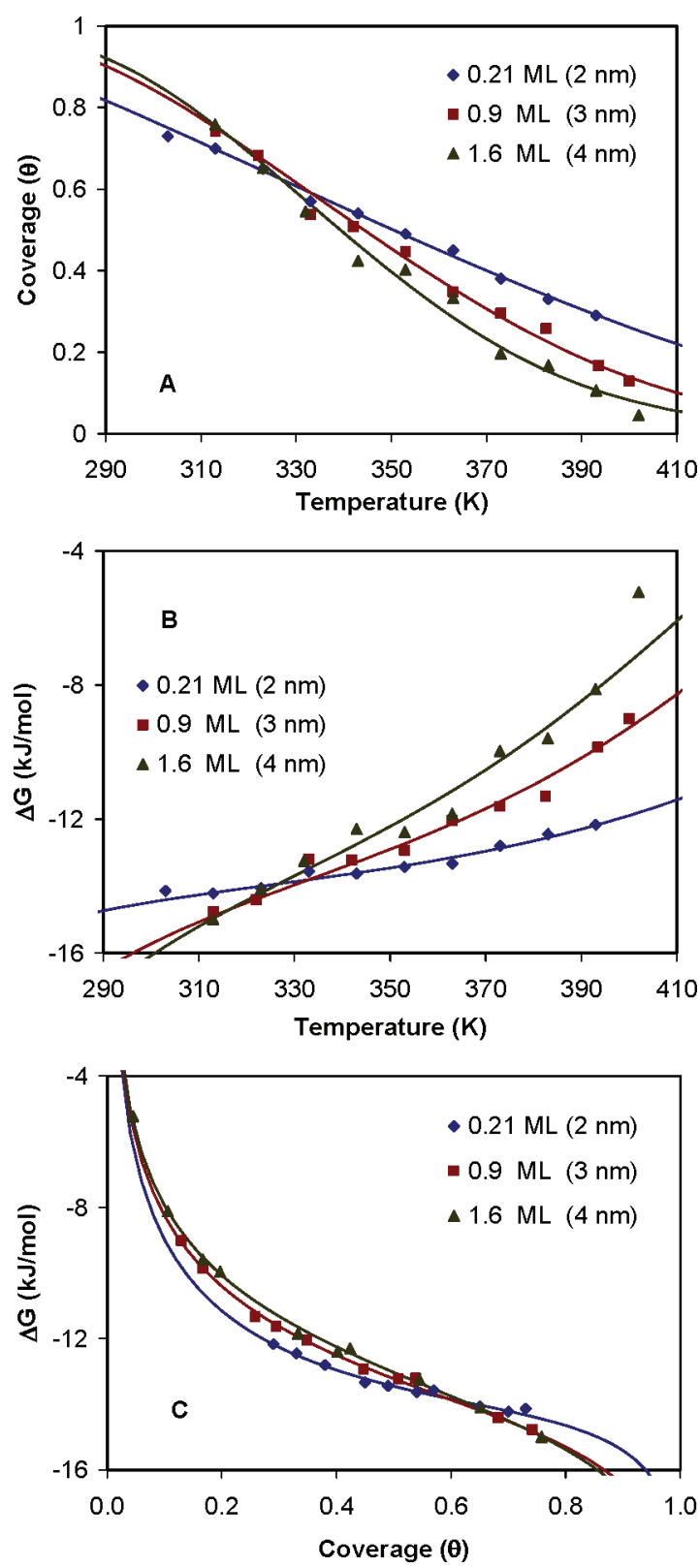

Figure 5. Application of the Temkin adsorbate interaction model to the $\mathrm{CO}$ adsorption on $\mathrm{Au} / \mathrm{TiO}_{2}$ model catalysts II from ref 23 . The particle size is reported as monolayer gold $(\mathrm{ML})$ and as average diameter $(\mathrm{nm})$. The isobaric $(P=10 \mathrm{mbar})$ coverage data $(A)$ come from polarization-modulation infrared reflection-absorption spectra. $\Delta G$ was calculated for each $(\theta, T)$ point in (A) according to the Temkin adsorbate interaction expression, eq 5 . The curves in (A)-(C) are from the fitting of all of the data, for each particle size, to one set of thermodynamic metrics $\left(\Delta H_{0}, \delta \Delta H\right.$, and $\left.\Delta S\right)$ according to the Temkin adsorbate interaction model; see Table 1 for values.

Behm. ${ }^{23}$ The agreement in $\Delta H_{0}$ values is excellent despite using different Temkin cases. Some of this may be artificial because our entropy term is held constant for the three particle sizes. From the Temkin analysis above for Goodman's data set of similar $\mathrm{Au} / \mathrm{TiO}_{2}$ model catalysts, we determined a trend in entropy with enthalpy. To test for trends in this data set, we imposed a reasonable variation in entropy with enthalpy and particle size $(\Delta S=-150,-130$, and $-110 \mathrm{~J} / \mathrm{K} \cdot \mathrm{mol}$ for smallest to largest particle size, respectively). Temkin fitting using these entropy values produced enthalpy values of $\Delta H_{0} / \delta \Delta H=78 /$
$24,63 / 10$, and $52 / 4 \mathrm{~kJ} / \mathrm{mol}$ for smallest to largest particle size, respectively. Thus, whether $\Delta S$ is held constant or allowed to vary in a reasonable way, the trend in enthalpy still stands: $\Delta H_{0}$ increases in magnitude with decreasing particle size, in very good agreement with the other $\mathrm{Au} / \mathrm{TiO}_{2}$ model catalyst analysis above. For these model catalysts, $\delta \Delta H$ also increases in magnitude with decreasing particle size.

\section{DISCUSSION}

As demonstrated by the fits in Figures $2-5$, the Temkin adsorbate interaction model accurately represents the data for the adsorption of $\mathrm{CO}$ on various gold real-world and model catalysts. For these rather different catalysts, the intrinsic enthalpy without adsorbate interactions varies as $-\Delta H_{0}=63-$ $75 \mathrm{~kJ} / \mathrm{mol}$. These values are in excellent agreement with previous enthalpy determinations, which vary from (-)62-76 $\mathrm{kJ} / \mathrm{mol}^{21-23}$ as listed in Table 1. Most of these catalysts utilize $\mathrm{TiO}_{2}$ as the support; however, there does not appear to be a significant support effect on $\Delta H_{0}$ provided similar particle sizes are examined. For example, the $\mathrm{Au} / \mathrm{Fe}_{2} \mathrm{O}_{3}$ (with $d=3.7 \pm 0.9$ $\mathrm{nm})$ and the $\mathrm{Au} / \mathrm{TiO}_{2}(d=3.8 \pm 0.8 \mathrm{~nm})$ catalysts from this study have essentially the same Au particle size and very comparable $\Delta H_{0}$ values (cf., -63.4 and $-66.0 \mathrm{~kJ} / \mathrm{mol}$, respectively). Most significant, $\Delta H_{0}$ does appear to vary approximately linearly with gold particle size, as displayed in Figure $6 .^{32}$

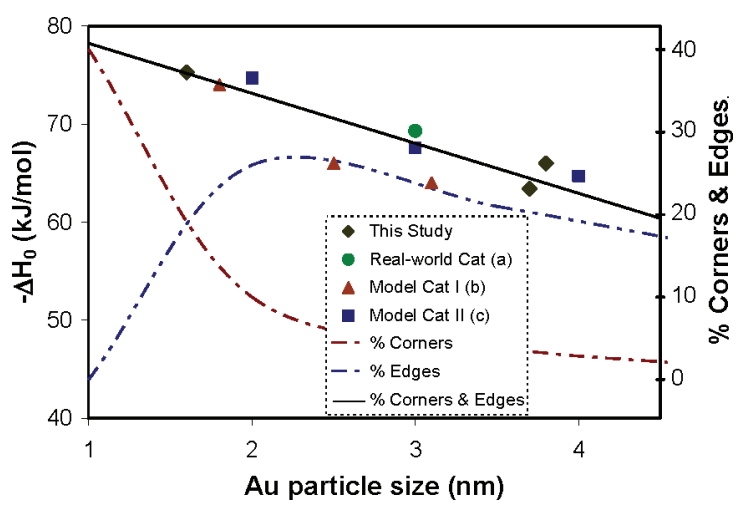

Figure 6. Summary of the adsorption enthalpy at zero CO coverage plotted (points) as a function of the gold particle diameter. The values are listed in Table 1, and the references for the literature data are (a) ref 22, (b) ref 21, and (c) ref 23. The curves are plots of the percent of gold corner and edges atoms to total surface atoms for each particle size; see text for details. ${ }^{14}$

As was previously discussed in detail, $\mathrm{CO}$ binds to two types of low-coordinate gold sites: $\mathrm{CN}=6$ corner atoms and $\mathrm{CN}=7$ edge atoms. ${ }^{2-15}$ Using the Wulff construction, Weststrate et al. have estimated the abundance of these low-coordinate sites relative to the total number of surface atoms for gold particles with $d=1-4.6 \mathrm{~nm} .{ }^{14}$ On the basis of their results (cf., Table 3 of ref 14), we have included a plot of the percent corner and edge sites as a function of gold particle size in Figure 6. The fraction of interface sites between the Au particle and support was not included. As expected, the distribution of corner and edge sites changes with $\mathrm{Au}$ particle size. Over this particle size range, as the particle size decreases, the percent corner sites continually increases, while the percent edge sites increases and then decreases for particles smaller than $\sim 2 \mathrm{~nm}$. Interestingly though, the sum of the two types of low-coordinate sites is 
effectively linear over this particle size range (cf., $\sim 1-5 \mathrm{~nm}$ ). These distributions are consistent with those published by Norskov et al. for "free" sites, that is, corner and edge sites not including the Au-support interface. ${ }^{5,33}$ It should be noted that the two scales in Figure 6, $\Delta H_{0}$ and \% corners and edges, have simply been aligned to cause the line for $\%$ corners and edges to pass through the $\Delta H_{0}$ data points.

Therefore, the intrinsic adsorption enthalpy $\Delta H_{0}$ correlates very well with the sum of corner and edge sites. This result can be interpreted as follows. For very small particles, for example, $d=1 \mathrm{~nm}$ with $40 \%$ of all Au surface atoms being $\mathrm{CN}=6$ corner sites and no edge sites, the enthalpy would be due to binding to corner sites (with $-\Delta H_{0} \approx 78 \mathrm{~kJ} / \mathrm{mol}$ ). For larger particles, for example, $d=4 \mathrm{~nm}$ with only $3 \%$ corner sites and $\sim 19 \% \mathrm{CN}=7$ edge sites, the enthalpy would reflect binding to mostly the edge sites (with $-\Delta H_{0} \approx 63 \mathrm{~kJ} / \mathrm{mol}$ ). For particle sizes between these limits, the enthalpy would be some type of average of these two based upon the relative abundance of corner and edge sites. The nearly linear distribution in Figure 6 then reflects these averages. It is important to note that each particle "size" is actually the average of a distribution of particles. Interestingly, when the percent of corner and edge sites equals zero, the $\Delta H_{0}$ value is predicted to be $-44 \mathrm{~kJ} / \mathrm{mol}$, corresponding to binding to the $\mathrm{CN}=8$ or 9 terrace sites. This is a reasonably small value, reflecting the observation that $\mathrm{CO}$ does not chemisorb to "flat" gold surfaces with $\mathrm{CN}=8$ or 9 sites. $^{16}$

The linear trend with particle size also suggests that the corner and edge sites on Au nanoparticles are not isolated but instead are coupled. Previously, we demonstrated that the Temkin adsorbate interaction model fits a distribution of two coupled binding sites, with the resulting thermodynamic metrics being an average of the adsorption enthalpy for the two sites. ${ }^{29}$ This is consistent with Figure 6. This idea of coupled binding sites is further supported by infrared spectroscopy studies from Boccuzzi's research group. ${ }^{3,16}$ They performed a thorough vibrational analysis for the adsorption of $\mathrm{CO}$ on various $\mathrm{Au}$ catalysts. Curve fitting of individual $\mathrm{CO}$ infrared spectra produced two peaks for $\mathrm{CO}$ bound to two sites, corners and edges. Analysis involving $\mathrm{CO}$ isotopes indicated that these $\mathrm{Au}-\mathrm{CO}$ binding sites are not isolated but are coupled. $^{3,16}$ Similarly, Weststrate et al. investigated CO adsorption on model $\mathrm{Au}$ catalysts using high-resolution photoemission spectroscopy of the Au $4 \mathrm{f}$ levels. ${ }^{14}$ Their results indicate that the $\mathrm{CO}$ adsorbs strongly on $\mathrm{CN}=6$ sites (small particles) and less strong on $\mathrm{CN}=7$ sites (larger particles). For small particles, the adsorption of $\mathrm{CO}$ affects the photoemission spectrum of all $\mathrm{Au}$ atoms in the particle. ${ }^{14}$ This would suggest that the Au binding sites are interacting or coupled in terms of $\mathrm{CO}$ adsorption.

Concerning the other Temkin metrics for these catalysts (see Table 1), the change in adsorption enthalpy with $\mathrm{CO}$ coverage varies as $-\delta \Delta H=7-40 \mathrm{~kJ} / \mathrm{mol}$. As mentioned above, $\delta \Delta H$ is an adsorption metric related to the adsorbate-substrate electronic interaction and how this interaction changes with surface coverage. For these varied data sets, there is no obvious trend in $\delta \Delta H$, and the variation in $\delta \Delta H$ values is probably due to support effects and/or differences in preparation methods and particle size distributions. It does appear, however, that those catalysts with the largest (magnitude) values of $\delta \Delta H$ (cf., this work and model catalysts I) are for data sets that extend to fairly low temperatures and may therefore reflect contributions due to physisorption at the very lowest temperatures.
Regarding the adsorption entropy, it varies as $-\Delta S=120-$ $160 \mathrm{~J} / \mathrm{K} \cdot \mathrm{mol}$. While the data sets are limited, the determined values do show a trend with $\Delta H_{0}$. In particular, stronger binding leads to larger (negative) adsorption entropies. Future experiments will focus on learning more about the $\delta \Delta H$ and $\Delta S$ adsorption metrics and how they can be used to characterize nanoparticle catalysts.

\section{CONCLUSION}

The adsorption of $\mathrm{CO}$ on the real-world catalysts $\mathrm{Au} / \mathrm{TiO}_{2}$, $\mathrm{Au} / \mathrm{Fe}_{2} \mathrm{O}_{3}$, and $\mathrm{Au} / \mathrm{ZrO}_{2}$ was examined under isobaric experimental conditions, and the adsorption coverage was measured using infrared transmission spectroscopy. The Temkin adsorbate interaction model accurately represented the adsorption data on these real-world gold catalysts. A full thermodynamic treatment of the Temkin adsorbate interaction model for the isobaric data involved three plots: coverage versus temperature, $\Delta G$ versus temperature, and $\Delta G$ versus coverage. These plots and the corresponding fits demonstrated a certain self-consistency of the Temkin adsorbate interaction model. Because each plot depends on the thermodynamic metrics in slightly different ways, unique and internally consistent thermodynamic values were determined from the adsorption data sets.

Additionally, we used this new treatment of the Temkin model to fit the data sets for the adsorption of $\mathrm{CO}$ on another $\mathrm{Au} / \mathrm{TiO}_{2}$ real-world catalyst, and on gold particles of model $\mathrm{Au} / \mathrm{TiO}_{2}$ catalysts (having different particle sizes) from two independent studies. The model fits the experimental data very well and produced meaningful thermodynamic metrics of enthalpy and entropy, which agreed with previous reports. In particular, the intrinsic adsorption enthalpy at zero $\mathrm{CO}$ coverage varies as $-\Delta H_{0} \approx 63-75 \mathrm{~kJ} / \mathrm{mol}$ and displays a linear trend with Au particle size. We suggest that the trend in this enthalpy metric reflects the relative contribution of both $\mathrm{CN}=6$ and 7 sites. For example, small particles would have more $\mathrm{CN}=6$ corner sites and stronger binding (cf., $-\Delta H_{0} \approx$ $78 \mathrm{~kJ} / \mathrm{mol}$ ), while larger particles would have more $\mathrm{CN}=7$ edge sites and weaker binding (cf., $-\Delta H_{0} \approx 63 \mathrm{~kJ} / \mathrm{mol}$ ). Furthermore, because the data sets can be represented by the Temkin adsorbate interaction model and the $\Delta H_{0}$ metric displays a linear trend with particle size, we suggest that the two binding sites are coupled in terms of their $\mathrm{CO}$ adsorption energetics.

The Temkin adsorbate interaction model appears to be most consistent with the physicochemical behavior and experimental data for $\mathrm{CO}$ adsorption on gold as thoroughly discussed previously. This new treatment of the Temkin adsorption model is straightforward and applicable to both isothermal and isobaric data sets. It provides meaningful thermodynamic metrics of enthalpy and entropy, which can be used to characterize and explain differences between various catalysts. The model should also be applicable to the adsorption of other small molecules on metal surfaces and particles that show coverage-dependence.

\section{AUTHOR INFORMATION}

\section{Corresponding Author}

*Phone: (210) 999-7381. E-mail: cpursell@trinity.edu.

\section{Notes}

The authors declare no competing financial interest. 


\section{ACKNOWLEDGMENTS}

We gratefully acknowledge the Italian Institute of Technology (Project SEED) for financial support of this work, along with the U.S. National Science Foundation (Grants CHE-0449549 and CHE-1012395) and the Robert A. Welch Foundation's Departmental Grant Program (Grant F-1529). C.J.P. also appreciatively acknowledges the financial support by Trinity University, the University of Torino, and the Italian Institute of Technology during his academic sabbatical.

\section{REFERENCES}

(1) Bond, G. C. L. C.; Thompson, D. T. Catalysis by Gold; Imperial College Press: London, 2006; Vol. 6.

(2) Boronat, M.; Concepcion, P.; Corma, A. J. Phys. Chem. C 2009, 113, 16772-16784.

(3) Chiorino, A.; Manzoli, M.; Menegazzo, F.; Signoretto, M.; Vindigni, F.; Pinna, F.; Boccuzzi, F. J. Catal. 2009, 262, 169-176.

(4) Hussain, A.; Curulla, F. D.; Gracia, J.; Nieuwenhuys, B. E.; Niemantsverdriet, J. W. Surf. Sci. 2009, 603, 2734-2741.

(5) Janssens, T. V. W.; Clausen, B. S.; Hvolbaek, B.; Falsig, H.; Christensen, C. H.; Bligaard, T.; Norskov, J. K. Top. Catal. 2007, 44, $15-26$.

(6) Jiang, T.; Mowbray, D. J.; Dobrin, S.; Falsig, H.; Hvolbaek, B.; Bligaard, T.; Noerskov, J. K. J. Phys. Chem. C 2009, 113, 1054810553.

(7) Lemire, C.; Meyer, R.; Shaikhutdinov, S.; Freund, H.-J. Angew. Chem., Int. Ed. 2004, 43, 118-121.

(8) Lopez, N.; Janssens, T. V. W.; Clausen, B. S.; Xu, Y.; Mavrikakis, M.; Bligaard, T.; Norskov, J. K. J. Catal. 2004, 223, 232-235.

(9) Lopez-Haro, M.; Delgado, J. J.; Cies, J. M.; del, R. E.; Bernal, S.; Burch, R.; Cauqui, M. A.; Trasobares, S.; Perez-Omil, J. A.; BayleGuillemaud, P.; Calvino, J. J. Angew. Chem., Int. Ed. 2010, 49, 19811985.

(10) McKenna, K. P.; Shluger, A. L. J. Phys. Chem. C 2007, 111, $18848-18852$.

(11) Mehmood, F.; Kara, A.; Rahman, T. S.; Henry, C. R. Phys. Rev. B: Condens. Matter Mater. Phys. 2009, 79, 075422/1-075422/6.

(12) Menegazzo, F.; Manzoli, M.; Chiorino, A.; Boccuzzi, F.; Tabakova, T.; Signoretto, M.; Pinna, F.; Pernicone, N. J. Catal. 2006, 237, 431-434.

(13) Weststrate, C. J.; Lundgren, E.; Andersen, J. N.; Rienks, E. D. L.; Gluhoi, A. C.; Bakker, J. W.; Groot, I. M. N.; Nieuwenhuys, B. E. Surf. Sci. 2009, 603, 2152-2157.

(14) Weststrate, C. J.; Resta, A.; Westerstroem, R.; Lundgren, E.; Mikkelsen, A.; Andersen, J. N. J. Phys. Chem. C 2008, 112, 6900-6906.

(15) Yim, W.-L.; Nowitzki, T.; Necke, M.; Schnars, H.; Nickut, P.; Biener, J.; Biener, M. M.; Zielasek, V.; Al-Shamery, K.; Kluener, T.; Baeumer, M. J. Phys. Chem. C 2007, 111, 445-451.

(16) Vindigni, F.; Manzoli, M.; Chiorino, A.; Boccuzzi, F. Gold Bull. 2009, 42, 106-112.

(17) Gottfried, J. M.; Schmidt, K. J.; Schroeder, S. L. M.; Christmann, K. Surf. Sci. 2003, 536, 206-224.

(18) Hartshorn, H.; Pursell, C. J.; Chandler, B. D. J. Phys. Chem. C 2009, 113, 10718-10725.

(19) Kim, J.; Samano, E.; Koel, B. E. J. Phys. Chem. B 2006, 110, $17512-17517$.

(20) Meier, D. C.; Bukhtiyarov, V.; Goodman, D. W. J. Phys. Chem. B 2003, 107, 12668-12671.

(21) Meier, D. C.; Goodman, D. W. J. Am. Chem. Soc. 2004, 126, $1892-1899$.

(22) Derrouiche, S.; Gravejat, P.; Bianchi, D. J. Am. Chem. Soc. 2004, 126, 13010-13015.

(23) Diemant, T.; Hartmann, H.; Bansmann, J.; Behm, R. J. J. Catal. 2007, 252, 171-177.

(24) Zhao, Z.; Diemant, T.; Rosenthal, D.; Christmann, K.; Bansmann, J.; Rauscher, H.; Behm, R. J. Surf. Sci. 2006, 600, 49925003.
(25) Dumas, P.; Tobin, R. G.; Richards, P. L. Surf. Sci. 1986, 171, 579-99.

(26) France, J.; Hollins, P. J. Electron Spectrosc. Relat. Phenom. 1993, 64-65, 251-8.

(27) Ruggiero, C.; Hollins, P. J. Chem. Soc., Faraday Trans. 1996, 92, 4829-4834.

(28) Ruggiero, C.; Hollins, P. Surf. Sci. 1997, 377-379, 583-586.

(29) Pursell, C. J.; Hartshorn, H.; Ward, T.; Chandler, B. D.; Boccuzzi, F. J. Phys. Chem. C 2011, 115, 23880-23892.

(30) Hayward, D. O.; Trapnell, B. M. W. Chemisorption, 2nd ed.; Butterworth \& Co.: WA, 1964.

(31) Masel, R. I. Principles of Adsorption and Reaction on Solid Surfaces; John Wiley \& Sons: New York, 1996.

(32) Because a distribution of particle sizes was reported in ref 22 (cf., $d=3-5 \mathrm{~nm}$ ), we chose the smallest diameter of $3 \mathrm{~nm}$ for this data set in Figure 6.

(33) Mavrikakis, M.; Stoltze, P.; Norskov, J. K. Catal. Lett. 2000, 64, 101-106. 